\title{
A CONSTITUIĈ̃O DA IDENTIDADE NEGRA NO LIVRO PARA INFÂNCIA BETINA, DE NILMA LINO GOMES
}

\author{
THE CONSTITUTION OF BLACK IDENTITY IN THE BOOK OF \\ CHILDREN'S BABY, BY NILMA LINO GOMES \\ LA CONSTITUCIÓN DE LA IDENTIDAD NEGRA EN EL LIBRO PARA
INFANCIA BETINA, DE NILMA LINO GOMES
}

Fabienne Neide da Cunha*

iD https://orcid.org/oooo-0oo2-7712-0145

Eliane Santana Dias Debus ${ }^{* *}$

https://orcid.org/oooo-0003-0555-2069

Joana Célia dos Passos ${ }^{* * *}$

iD https://orcid.org/oooo-0001-9946-7900

\begin{abstract}
REVISTA PEDAGÓGICA
Revista do Programa de Pós-graduação em Educação da Unochapecó | ISSN 1984-1566

Universidade Comunitária da Região de Chapecó | Chapecó-SC, Brasil

Como referenciar este artigo: CUNHA, F. N.; DEBUS, E. S. D.; PASSOS, J. C. A constituição da identidade negra no livro para infância Betina, de Nilma Lino Gomes. Revista Pedagógica, Chapecó, v. 22, p. 1-21, 2020.

DOI: http://dx.doi.org/10.22196/rp.v22io.4570
\end{abstract}

Resumo: A Lei ${ }^{\circ}$ 10.639, de 2003, é uma das Políticas de Ações Afirmativas que incidiu diretamente na educação para as relações étnico-raciais, visando fomentar nos(as) profissionais da educação novas lentes para o ensino de história e da literatura afro-brasileira, servindo como um dispositivo impulsionador para mobilizar a cidadania e descortinar as práticas racistas ainda presentes nos ambientes educacionais e na sociedade. Dessa maneira, faz-se alguns questionamentos: a produção literária para a infância pode problematizar as relações étnicoraciais? Ela é capaz de contribuir para a valorização e a constituição identitária do(a) criança negro(a)? Assim, acreditando positivamente, o presente artigo traz à cena o livro Betina, de Nilma Lino Gomes, buscando evidenciar na sua construção textual, em particular por meio do protagonismo negro infantil, um discurso em que os preconceitos raciais são (re)significados, possibilitando que ocorra a constituição identitária de negros e negras, desde a infância, sob uma perspectiva desprovida das marcas inferiorizantes advindas do racismo.

Palavras-chave: Identidade negra. Infância. Literatura afro-brasileira. Educação das relações étnico-raciais.

Abstract: The Law n. 10.639/2003 is one of the Affirmative Action Policies that focused directly on education for ethnic-racial relations, aiming to foster in education professionals new lenses for teaching history and Afro-Brazilian literature, serving as a driving force to mobilize citizenship and unveil racist practices still present in educational environments and society. Can literary production for childhood problematize ethnicracial relations? Is it capable of contributing to the valorization and the identity constitution of the black child? Believing positively, the present article brings to the scene the book Betina, by Nilma Lino Gomes, seeking to evidence in its textual construction, in particular through the black child protagonism, a discourse in which racial prejudices are (re)meanings allowing the occurrence of identity of blacks and blacks, from childhood, from a perspective devoid of the inferior marks of racism.

Keywords: Black identity. Childhood. Afro-Brazilian literature. Education of ethnic-racial relations.

Resumen: La Ley n· 10.639/2003 es una de las Políticas de Acciones Afirmativas que se centró directamente en la educación para las relaciones étnico-raciales, con el objetivo de fomentar en los nuevos profesionales de la educación nuevas lentes para la enseñanza de la historia y la literatura afro-brasileña, sirviendo como un " dispositivo impulsor para movilizar la ciudadanía y descortinar las prácticas racistas aún presentes en los ambientes educativos y en la sociedad. ¿̇La producción literaria para la infancia puede problematizar las relaciones étnico-raciales? ¿Es capaz de contribuir a la valorización y la constitución identitaria del / el niño negro / a? En el presente artículo trae a la escena el libro Betina, de Nilma Lino Gomes, buscando evidenciar en su construcción textual, en particular por medio del protagonismo negro infantil, un discurso en que los prejuicios raciales son (re)significados posibilitando que ocurra la constitución identitaria de negros y negras, desde la infancia, desde una perspectiva desprovista de las marcas inferiorizantes derivadas del racismo.

Palabras claves: Identidad negra. La infancia. Literatura afro-brasileña. Educación de las relaciones étnico-raciales. 


\section{Introdução}

O que é literatura? O que é literatura afro-brasileira? Qual o papel da literatura na formação para a educação das relações étnico-raciais? Qual o impacto da Lei $\mathrm{n}^{\circ}$ 10.639, de 2003 (BRASIL, 2003), no contexto da sociedade brasileira, em particular no que diz respeito aos livros para infância e à inserção da cultura africana e afro-brasileira? A produção literária para infância pode problematizar as relações étnico-raciais e contribuir para a valorização da identidade negra? Tais indagações, caso não respondidas, são propulsoras do diálogo que estabelecemos neste texto, no qual buscamos nos debruçar sobre o livro Betina, de Nilma Lino Gomes (2009), verificando como ele apresenta o protagonismo negro infantil e como o discurso (textual e visual) pode, ou não, colaborar para a constituição identitária do leitor.

A compreensão do significado de literatura é necessária para o iniciarmos este texto, embora não seja tarefa fácil, de acordo com Umberto Eco (2003, p. 11), “A literatura, contribuindo para formar língua, cria identidade e comunidade", pois se manifesta no seio das diferentes culturas e sociedades, sendo todas criações realizadas pelo homem, seja pela vertente do drama, do poético ou do ficcional. Nas palavras de Antonio Candido (2011, p. 176), a literatura é:

[...] da maneira mais ampla possível, todas as criações de toque poético, ficcional ou dramático em todos os níveis de uma sociedade, em todos os tipos de cultura, desde o que chamamos de folclore, lenda, chiste, até as formas mais complexas e difíceis da produção escrita das grandes civilizações.

Desse modo, é inerente à condição humana a fabulação (Candido, 2011), não sendo possível ao homem viver sem a literatura e sem o seu encontro com as diversas expressões que a mesma se corporifica na conjuntura da sociedade.

A literatura é arte na sua feitura. O texto literário humaniza o homem, assim detém um papel importante, ampliando sua ótica acerca do mundo, propiciando para o mesmo acrescer seu modo de viver, sentir, adquirir conhecimentos, engendrar reflexões e, ainda, construir as relações sociais. Para Candido (2011, p. 179, grifo do autor), "Toda obra literária é antes de mais nada uma espécie de objeto, de objeto construído; e é grande o poder humanizador desta construção, enquanto construção". Sobre a compreensão de humanização, fazemos uso da explicitação do autor, que nos diz que é:
* Mestranda no Programa de Pós-Graduação em Educação - PPGE/UFSC Integrante do Núcleo de Estudos e Pesquisas sobre as Violências - NUVIC/ UFSC e o Grupo de Estudos Alteritas: Diferença, Arte e Educação.

E-mail: fabyzinhaaa@gmail.com.

** Doutora em Linguística e Letras pela Pontifícia Universidade Católica do Rio Grande do Sul (2001) e Pós-doutora na Universidade do Minho (PT). Professora da Universidade Federal de Santa Catarina - Programa de Pós-Graduação em Educação e Programa de Pós-Graduação em Estudos da Tradução.

E-mail: elianedebus@hotmail.com

*** Doutorado em Educação (2010) pela Universidade Federal de Santa Catarina e Pós-doutora em Sociologia Política no PPGSP/UFSC. Docente no Departamento de Estudos Especializados em Educação do Centro de Ciências da Educação/ UFSC.

E-mail:passos.j.c@gmail.com 
[...] um processo que confirma no homem aqueles traços que reputamos essenciais, como o exercício da reflexão, a aquisição do saber, a boa disposição para com o próximo, o afinamento das emoções, a capacidade de penetrar nos problemas da vida, o senso da beleza, a percepção da complexidade do mundo e dos seres, o cultivo do humor. A literatura desenvolve em nós a quota de humanidade na medida em que nos torna mais compreensivos e abertos para a natureza, a sociedade, $o$ semelhante. (CANDIDO, 2011, p. 182).

No bojo de cada sociedade se criam diferentes expressões literárias (dramáticas, poéticas ou ficcionais), de acordo com as diferentes culturas incutidas nas mesmas, "[...] de acordo com os seus impulsos, as suas crenças, os seus sentimentos, as suas normas, a fim de fortalecer em cada um a presença e atuação deles" (CANDIDO, 2011, p. 177).

Sendo patrimônio cultural de uma sociedade, a literatura é feitura de mãos de homens e mulheres que vivem (n)esta sociedade e escrevem para outros homens e outras mulheres (independente de idades). Interessa-nos pensar aqui uma literatura escrita por negros e negras, que tematizem as relações de personagens negras e lida por toda gente. Essa tarefa também não é fácil e não está dada. Assim, dentro dos discursos literários encontramos definições distintas para essa literatura, como: literatura negra (Bernd, 1988), literatura afro-brasileira (Duarte, 2010).

Na ótica de Zilá Bernd (1988, p. 22, grifo da autora), "O conceito de literatura negra não se atrela nem à cor da pele do autor nem apenas à temática por ele utilizada, mas emerge da própria evidência textual cuja consistência é dada pelo surgimento de um eu enunciador que se quer negro". Na literatura, ainda tem sido comum a imagem estereotipada de personagens negros e negras, que retrata as perversas relações racistas, evidenciando a sua condição de oprimido nas relações sociais estabelecidas na sociedade. Octavio Ianni (1988), no seu entendimento sobre a literatura negra e sua eclosão, observa que:

A literatura negra é um imaginário que se forma, articula e transforma no curso do tempo. Não surge de um momento para outro, nem é autônoma desde o primeiro instante. Sua história está assinalada por autores, obras, temas, invenções literárias. É um imaginário que se articula aqui e ali, conforme o diálogo de autores, obras, temas e invenções literárias. É um movimento, um devir, no sentido de que se forma e transforma. Aos poucos, por dentro e por fora da literatura 
brasileira, surge a literatura negra, como um todo com perfil próprio, um sistema significativo. (IANNI, 1988, p. 91).

A literatura afro-brasileira, nas palavras de Eduardo de Assis Duarte (2010, p. 113), configura-se do seguinte modo, "[...] ela é tanto contemporânea, quanto se estende a Domingos Caldas Barbosa, em pleno século XVIII; tanto é realizada nos grandes centros, com dezenas de poetas e ficcionistas, quanto se espraia pelas literaturas regionais". Em outras palavras, "[...] essa literatura não só existe como se faz presente nos tempos e espaços históricos de nossa constituição enquanto povo; não só existe como é múltipla e diversa" (DUARTE, 2007, p. 1). Ou seja, é uma literatura que perpassou os séculos e que se encontra enraizada na história do povo negro desde os seus ancestrais, embasa-se em sua própria cultura, na sua linguagem, na sua relação com a sociedade racista e segregadora, na qual a ideologia se alicerça.

Sobre o surgimento da literatura negra, Bernd (1988, p. 22-23, grifo da autora) ressalta que "[...] surge como tentativa de preencher vazios criados pela perda gradativa de identidade determinado pelo longo período em que a 'cultura negra' foi considerada fora-da-lei”. Em outras palavras, a cultura dominante era do homem branco colonizador e eurocêntrico, onde toda ou qualquer cultura diferente era desconsiderada.

Sob a perspectiva de Ianni (1988), os escritores negros e as escritoras negras utilizam-se de dispositivos ideológicos para realizarem o resgate de sua história, desnublar o ambiente, engendrar os seus temas, perquirir as diferentes linguagens, apurar a matéria que servirá para a sua criação e construir a clareza da relação do micro com o macro Isto é, do seu individual para com o seu eu coletivo. A ideologia e a cultura que dominam a sociedade brasileira e o mundo escamoteiam as verdades: a "[...] história incruenta, escravidão açucarada, democracia racial etc.” (IANNI, 1988, p. 93).

A literatura afro-brasileira, segundo Duarte (2010), possui algumas características específicas que a classificam no âmbito da literatura supracitada, por possuir:

[...] uma voz autoral afrodescendente, explícita ou não no discurso; temas afro-brasileiros; construções linguísticas marcadas por uma afro-brasilidade de tom, ritmo, sintaxe ou sentido; um projeto de transitividade discursiva, explícito ou não, com vistas ao universo recepcional; mas, sobretudo, um ponto de vista ou lugar de enunciação política e culturalmente identificado à afrodescendência, como fim e começo. (DUARTE, 2010, p. 122, grifo do autor). 
Dessa maneira, a escrita do autor(a) negro(a) é totalmente autoral, é uma escrita marcada pelas histórias de vida e luta do povo negro, é uma história perpassada por particularidades que essa população sentiu e sente sob a pele. Os efeitos e as marcas da discriminação, do racismo, das desigualdades sociais e do preconceito se encontram presentes, implicitamente ou explicitamente, nos textos literários desses autores que reconhecem o seu local de pertencimento.

No ponto de vista de Gregorin Filho (2016, p. 69), "[...] a literatura configura-se como um importante documento para a compreensão de relações culturais e de conflitos sociais que, por este ou aquele motivo, foram apagados de textos responsáveis pelo saber histórico, sociológico ou antropológico". Acreditamos que a literatura, para além do texto literário, é um fio condutor para desenvolver no indivíduo novos modos de conceberem o mundo. Essa literatura é aquela que perpassa o texto e vai além, incidindo no corpo do sujeito novos modos de conceberem o mundo e as relações sociais que estão em seu entorno. Eliane Debus (2017, p. 38) ressalta que "O texto literário partilha com os leitores, independentemente da idade, valores de natureza social, cultural, histórica e/ou ideológica por ser uma realização da cultura e estar integrado num processo comunicativo".

Em diálogo com os demais estudiosos, mas se detendo no livro literário para infância, a autora demarca o recente interesse pelo tema, depois dos trabalhos iniciais de Rosemberg (1985) na década de 1980, categorizando os títulos comercializados no mercado editorial brasileiro em:

1) Literatura que tematiza a cultura africana e afro-brasileira;

2) Literatura afro-brasileira - escrita por aqueles que se identificam como afro-brasileiros;

3) Literaturas africanas.

$\mathrm{Na}$ primeira categoria, a literatura apresenta como temática a cultura africana e afro-brasileira, "[...] sem focalizar aquele que escreve (a autoria), mas, sim, o que tematiza" (DEBUS, 2017, p. 33). Na segunda, estaria a escrita pelo escritor afro-brasileiro centrada naquele que escreve. Já a terceira, a escrita estaria centrada naquela produzida por escritores oriundos do continente africano e que pode gerar subcategorias referentes aos diferentes países/línguas e gêneros.

Desse modo, ao trabalharmos com Betina, de Nilma Lino Gomes (2009), adotamos a categorização de literatura afro-brasileira para infância, pois, para além da tematização da cultura africana e afro-brasileira, o livro é escrito por uma mulher negra. O título em tela foi publicado no ano de 2009, ou seja, faz parte das edições produzidas pós 
Lei $\mathrm{n}^{0}$ 10.639, de 2003, e demais documentos oriundos dessa (BRASIL, 2003).

\section{A relevância da Lei $n^{\circ} 10.639 / 2003$ e a sua importância para a educação das relações étnico-raciais}

Com o advento da Lei $\mathrm{n}^{\circ}$ 10.639/2003 (BRASIL, 2003), que alterou a Lei $n^{\circ}$ 9.394, 1996 (BRASIL, 1996), ao incluir a obrigatoriedade do ensino da História da África e Cultura Afro-brasileira na Educação Básica, o contexto educacional brasileiro tem a oportunidade de rever seu currículo e reconhecer a hegemonia eurocêntrica na seleção dos conhecimentos. Por esse motivo, a referida Lei ${ }^{\circ}$ 10.639/2003 constitui-se como uma política de Ação Afirmativa, que "[...] reconhece a diversidade étnico-racial, valoriza a história e a cultura dos povos negros e se propõe a construir uma educação antirracista, sem sombra de dúvidas, trouxe avanços para essas discussões no espaço escolar, no entanto, a sua aceitação não é unânime [...]" (DEBUS, 2017, p. 53).

Como muito bem cita a autora, a referida lei conduziu muitas mudanças positivas no contexto educacional brasileiro, mesmo que sua implementação nas práticas pedagógicas não se realize de maneira adequada. Quer dizer, muitos docentes ainda se encontram engessados e com as mãos amarradas com relação ao ensino da História da África e Cultura Afro-Brasileira e em como ensiná-las para as crianças, jovens e adultos, pois partem de conhecimentos prévios colonizadores, trazendo a figura da população negra como subalterna e inferior. Diante disso, o trabalho pedagógico não pode ser neutro, ele deve ser atravessado por ações pedagógicas que promovam a conscientização e reflexão dos discentes. No entanto, encontramos nas redes de ensino uma parcela de professores que não abarcam as questões étnico-raciais e, quando o fazem, mostram-se despreparados para tal ação. Porém, apesar de ser minoria, existem docentes que buscam legitimar a Lei $\mathrm{n}^{0}$ 10.639/2003 em suas ações pedagógicas.

A educação das relações étnico-raciais, de acordo com Petronilha Beatriz Gonçalves e Silva (2007), é aquela voltada para o desenvolvimento de uma sociedade que possua sujeitos, sem fazer menção ao gênero, que promova o pensamento e ações reflexivas sobre os direitos que os(as) cidadãos(ãs) possuem e, ainda, acerca das condições de igualdade na sociedade.

A educação das relações étnico-raciais tem por alvo a formação de cidadãos, mulheres e homens empenhados em promover condições de igualdade no exercício de direitos 
sociais, políticos, econômicos, dos direitos de ser, viver, pensar, próprios aos diferentes pertencimentos étnico-raciais e sociais. Em outras palavras, persegue o objetivo precípuo de desencadear aprendizagens e ensinos em que se efetive participação no espaço público. Isto é, em que se formem homens e mulheres comprometidos com e na discussão de questões de interesse geral, sendo capazes de reconhecer e valorizar visões de mundo, experiências históricas, contribuições dos diferentes povos que têm formado a nação, bem como de negociar prioridades, coordenando diferentes interesses, propósitos, desejos, além de propor políticas que contemplem efetivamente a todos (SILVA, 2007, p. 490, grifos nossos).

O Brasil é um país multicultural, nele encontramos uma ampla diversidade que "[...] não foi e hoje o é, com muita dificuldade aceita” (SILVA, 2007, p. 493), em que se encontram presentes nos grupos étnico-raciais que constituem a sociedade brasileira - negros, indígenas, asiáticos, europeus -, e é no seio das relações sociais que é concebida a construção da identidade dos sujeitos inferiorizados, marginalizados e oprimidos. Silva (2007, p. 491), pontua que:

[...] construímos nossas identidades - nacional, étnico-racial, pessoal -, apreendemos e transmitimos visão de mundo que se expressa nos valores, posturas, atitudes que assumimos, nos princípios que defendemos e ações que empreendemos. [...] [Nós] aprendemos a nos situar na sociedade, bem como o ensinamos a outros e outras menos experientes, por meio de práticas sociais em que relações étnico-raciais, sociais, pedagógicas nos acolhem, rejeitam ou querem modificar.

Desse modo, o papel docente é fundamental para alicerçar a educação das relações étnico-raciais de modo que os(as) estudantes sejam capazes de compreender que não vivemos numa sociedade monocultural, ao contrário, somos partícipes de uma sociedade multicultural, com direitos e deveres. Assim, devemos descortinar a ideia de que possuímos apenas "[...] uma única raiz étnico-racial" (SILVA, 2007, p. 501). Pensar dessa maneira nos cristaliza e aprisiona no ato mecânico de ensinar "[...] conteúdos tidos como os mais perfeitos e completos que a humanidade já teria produzido" (SILVA, 2007, p. 501). A autora sabiamente disserta que: 
Tornamo-nos incapazes de perceber as vozes e imagens ausentes dos currículos escolares: empobrecidos, mulheres, afrodescendentes, africanos, indígenas, idosos, homossexuais, deficientes, entre outros. Para superar a tudo isto, precisamos ultrapassar estereótipos, extinguir preconceitos, e como disse Senhor, em um de seus poemas, proceder a uma “desintoxicação semântica”, isto é, redefinir termos e conceitos, por exemplo, no nosso caso do campo educacional, a começar por educação, aprender, ensinar, saber, educar, educar-se (SILVA, 2007, p. 501).

Almejar e acreditar que no futuro a educação das relações étnico-raciais seja concebida em sua plenitude, com o intuito de formar cidadãos que, de fato, venham a fomentar uma sociedade brasileira com menos racismo, discriminações sociais e preconceitos. Não é uma tarefa fácil o processo de ensinar e aprender na sociedade brasileira. $\mathrm{Na}$ ótica de Silva (2007, p. 492), “[...] se vê, é complexa, mas não impossível, a tarefa de tratar de processos de ensinar e de aprender em sociedades multiétnicas e pluriculturais, como a brasileira". Entretanto, se a sociedade brasileira em especial, os docentes, voltando para nossa ótica no âmbito educacional - começar a modificar suas posturas e visões de mundo dentro do campo educacional, será possível viver numa sociedade mais igualitária para todos, "abertos a nossa diversidade, sem querer ninguém ser o melhor, o superior" (SILVA, 2007, p. 502).

Para essas mudanças paulatinas, sem dúvida, a literatura tem uma importância fundamental, para isso a necessidade de livros que apresentem uma representação pluriétnica de personagens, e é nesse contexto que inserimos Betina, de Nilma Lino Gomes.

\section{Nas tranças da menina, um mundo a conhecer}

Betina foi trançada pelas mãos negras de Nilma Lino Gomes (2009), intelectual negra e estudiosa das questões étnico-raciais, que nasceu em Belo Horizonte no dia 13 de março de 1961. A autora é Pedagoga (1988) e Mestra (1994) pela Universidade Federal de Minas Gerais (UFMG), bem como Doutora (2002) em Antropologia Social pela Universidade de São Paulo (USP). Possui Pós-Doutorado em Sociologia pela Universidade de Coimbra (2006). Anterior a sua saída do país foi presidente da Associação Brasileira de Pesquisadores Negros (ABPN) (2004/2006). Foi a primeira mulher negra a ser nomeada reitora da Universidade da Integração Internacional da Lusofonia Afro-Brasileira (2013/2014). Dentre tantas atuações e publicações, Gomes, no ano de 2009, lança Betina, com ilustrações de Denise 
Nascimento, brindando e convidando o público a deleitar-se no universo da literatura afro-brasileira para a infância com a história da "Betina-menina-trançadeira que virou Betina-mulher-cabeleireira” (GOMES, 2009, p. 18). Para além desse título, Gomes escreveu para infância o livro $O$ menino coração de tambor (2013), ilustrado por Mauricio Negro, ambos lançados pela chancela da Mazza Edições.

As ilustrações de Betina são realizadas pelas hábeis mãos negras de Denise Nascimento, graduada no Curso de Designer pela Universidade do Estado de Minas Gerais (1992), e que desde o ano de 1998 se dedica a ser ilustradora de livro infanto-juvenil ${ }^{1}$. Os desenhos de Nascimento são caracterizados por respeitar os traços fenotípicos do negro, fazendo emergir ilustrações muito bem elaboradas e impactantes. Segundo Debus (2017, p. 37), “[...] a ilustração tem papel intrínseco nas publicações e é lida também como narrativa [...]". Ou seja, as ilustrações compõem a obra literária e são ferramentas indispensáveis para tecer a história. Sobre a existência de personagens negras ou da presença da cultura africana em obras da literatura, a autora esclarece que a:

[...] presença de personagens negras ou de elementos da cultura africana e afro-brasileira em narrativas de recepção infantil e juvenil, produzidas no Brasil, quase inexiste anteriormente a década de 1970, e, quando isso ocorre, o negro é representado com docilidade servil, submisso ao cumprimento de seu papel de subalternidade [...]. (DEBUS, 2017, p. 39).

Em vista disso, acreditamos que as ilustrações do livro Betina não fazem alusão ao negro de forma inferiorizada e subalterna, tal qual consta no excerto. Ao contrário, a ilustradora ressalta a beleza negra e nos mostra o quanto é belo ser negra(o) e, também, através de sua delicadeza, brinda-nos com imagens que nos transportam para além do imaginário.

Os estudiosos que pesquisam assuntos que estão atrelados às questões étnico-raciais conhecem as ações e a importância que Nilma Lino Gomes nesse espaço. Lugar este marcado por lutas históricas, no qual a população negra busca ter seu local de pertencimento na sociedade capitalista brasileira, que é racista e que ilegítima implicitamente ou explicitamente a presença do negro em seu contexto. Infelizmente, o racismo estrutura as relações sociais nessa sociedade em que o opressor coage o oprimido. A autora afirma que "[...] o racismo em nossa sociedade se dá de um modo muito especial: ele se afirma através da sua
1 Dados extraídos do site Editora Elementar. Disponíveis em: <https://www. editoraelementar.com.br/ilustradores/61/Denise-Nascimento> . Acesso em: 9 dez. 2017. 
própria negação" (GOMES, 2005, p. 46). Isto é, o negro não é reconhecido como um cidadão de direitos e deveres.

O livro de Gomes (2009) narra a história da menina Betina e sua relação de afetividade com a sua avó e traz a ligação com os costumes ancestrais do povo negro, que são passados de gerações para gerações. Assim que abrimos o livro, deparamo-nos com a imagem inicial de Betina brincando de pular corda com mais duas amigas, uma negra e a outra branca. Na página subsequente, encontramos uma linda ilustração da menina pulando corda e como texto a letra da música que embala a brincadeira. Em seguida, ela surge contente e feliz na Rua Minervina, onde a avó se encontra no parapeito da janela de sua casa. São páginas que antecipam o relato e provocam uma aproximação sensível entre o leitor e as personagens da fabulação.

A narrativa, tecida pelos fios da visibilidade da etnia negra da personagem, introduz o questionamento sobre quem a "[...] fez tão bonitinha: foi o sol, foi a lua ou as estrelas miudinhas" (GOMES, 2009, p. 4-5), configurando uma forma positiva de inserção. O momento de diálogo tem início quando Betina está em casa e sua avó começa o processo de trançar seu cabelo. A menina encontra-se sentada numa almofada grande de cor vermelha e brinca com uma boneca negra de cabelos trançados. A avó sentada num banco de madeira de cor verde com pequenas florzinhas azuis desenhadas em sua lateral, com todo cuidado lava, seca e divide o cabelo em mechas para fazer as tranças, usando um pente de madeira com dentes grossos para desembaraçar os cabelos e também produtos próprios para cabelos crespos.

Nos gestos de dedicação e morosidade, a avó demonstra adorar esse momento com a neta, pois é feito de troca de afetos, dizeres e cantares. A avó faz uso desse tempo com a neta para lhe contar histórias de suas ancestrais, como, por exemplo, da arte de trançar os cabelos. Mesmo colocando toda afetividade e cuidado nos momentos de penteados, ela percebia que Betina demonstrava sentir um pouco de dor no ato de trançar o cabelo. Apesar disso, quando o penteado estava finalmente pronto, a menina sentia-se muito bem e corria para frente do espelho. A menina admirava o penteado novo e ficava feliz com a imagem refletida no espelho: "Ela sempre gostava do que via. Do outro lado do espelho, sorria para ela uma menina negra, com dois olhos grandes e pretos como jabuticabas, um rosto redondo e bochechas salientes [...]" (GOMES, 2009, p. 8). A mãe de Betina alegrava-se ao ver a filha feliz e percebia o carinho e respeito que a menina tinha pela avó e o grande amor que a avó sentia pela neta.

Betina era elogiada por seus cabelos cheirosos e pelas lindas tranças e, imediatamente, remetia a sua feitura 
as hábeis mãos de sua avó. Na escola os seus colegas também comentavam acerca do seu cabelo e dos penteados que usava, alguns não gostavam e acabavam torcendo o nariz e puxavam as suas tranças, mas ela não deixava passar em vão essas atitudes e enfaticamente falava: "Para com isso! Tá com inveja, é?! Se quiser, peço a minha avó para fazer trancinha no seu cabelo também" (GOMES, 2009, p.12). Contudo, a professora estimulava-a a ter suas tranças mesmo com os comentários contrários, com ações preconceituosas e racistas.

A menina Betina demonstrava conhecer as técnicas do ato de trançar, pois no recreio as colegas chegavam até ela para perguntar como as tranças eram feitas. Prontamente, explicava que elas podem ser realizadas em qualquer cabelo, porém, o comprimento era importante para tal ação, porque "[...] se o cabelo estiver curto ou for muito liso, é preciso emendar com um pouco de cabelo comprado na loja" (GOMES, 2009, p. 12), que são "os cabelos com fios postiços" e, que segundo a sua avó, "[...] as atrizes das novelas vivem fazendo isso! Emendam os cabelos [...]" (GOMES, 2009, p. 12).

O tempo foi passando, Betina cresceu e a avó conta para a neta que daqui a algum tempo irá encontrar os ancestrais. Estes que deixaram para o povo negro os seus costumes, tradições e histórias de luta contra uma sociedade branca que os segregavam e os escravizavam. Antes de ir a esse encontro, a avó deixa-lhe um presente: ensina a trançar os cabelos. No entanto, ela ensina com uma condição: "Você vai trançar o cabelo de toda a gente, ajudando cada pessoa que chegar até você a se sentir bem, gostar mais de si, sentir-se feliz de ser como é, com o seu cabelo e a sua aparência" (GOMES, 2009, p. 16). Assim, Betina honrou a condição que a avó lhe fez, tornou-se dona de um salão de beleza e trançava cabelos de todos os tipos, de pessoas negras, brancas e de quem mais se interessasse pelas tranças. Quando se recordava de sua avó sempre se emocionava, pois engendrou conhecimentos advindos de uma mulher negra muito sábia: "Se a minha avó estivesse aqui, ela ia ficar orgulhosa!” (GOMES, 2009, p. 18).

Anos depois, Betina-mulher recebe um telefonema e, para sua surpresa, era a diretora da Escola Municipal Pixinguinha, onde estudara, e faz-lhe o convite de realizar uma palestra sobre "a arte de pentear e traçar" (GOMES, 2009, p. 20).

A arte de trançar os cabelos que aprendera com a sua avó, que havia apreendido com a sua mãe, a qual apreendeu com os seus antepassados e que foi passando de geração para geração como uma herança, agora eram motivo de retorno ao espaço de sua infância, onde, por vezes, teve de lidar com embates raciais. De roupa nova, sapato de salto 
alto e com o cabelo todo trançado, Betina agora mulher se encontra com outras tantas meninas que fazem rememorar a Betina-criança.

Na roda de conversa trouxe seu dizer ancestral sobre a feitura do trançado nas mulheres de sua família. Foi então que "uma adolescente com jeito indígena" falou: "Ah! Então, uma ensinava a outra!” (GOMES, 2009, p. 22). Assim, Betina concluiu: "É isso mesmo! Na história da minha família, a arte das tranças foi ensinada de mãe para filha, de tia para sobrinha, de avó para neta e assim por diante. Uma mulher foi ensinando para a outra até chegar a mim [...]" (GOMES, 2009, p. 22).

A história tem seu desfecho com Betina palestrando e explicitando para todos os presentes que existem heranças que são perpassadas por gerações e, ainda, que a sua relação com o seu cabelo e com a sua cor da pele negra é motivo de orgulho, pois se sente feliz em ser quem é: uma mulher negra trançadeira.

\section{As especificidades na obra Betina: uma breve análise das questões étnico-raciais e da construção da identidade negra}

A narrativa do livro Betina (GOMES, 2009) traz à tona questões acerca da ancestralidade e da importância da história oral e da memória, aludindo à construção da identidade negra, na qual a relação da neta com a avó é de fundamental importância para que seja possível deter o conhecimento e seja capaz de compreender que ser negra e possuir cabelo crespo não são sinônimos de feiura, mas, sim, de orgulho.

É o resgate da história oral do povo negro que faz com que a protagonista da história venha a conhecer a cultura africana e, ainda, serve de alicerce para que a mesma possa construir ou reconstruir a sua identidade como sendo mulher negra.

Relatar acontecimentos passados é, muitas vezes, reportar-se ao remoto, ação da qual rememorar determinados fatos causam dor, inquietações, angústias e até mesmo aversão. Para recontarmos algo que nos foi dito tempos atrás, devemos recorrer a nossa memória e, fazendo uso dela, os indivíduos conseguem recontar as histórias que são perpassadas pelas gerações. Acerca do conceito de memória, Margarida de Souza Neves (1998, p. 218) disserta:

[...] na memória se cruzam passado, presente e futuro; temporalidades e espacialidades; monumentalização e documentação; dimensões materiais e simbólicas; identidades e projetos. É crucial porque na memória se entrecruzam a lembrança e o esquecimento; 
o pessoal e o coletivo; o indivíduo e a sociedade, o público e o privado; o sagrado e o profano. Crucial porque na memória se entrelaçam registro e invenção; fidelidade e mobilidade; dado e construção; história e ficção; revelação e ocultação.

Logo, sem a memória não iríamos ser conhecedores das histórias que aconteceram pelo mundo. É através da memória que podemos conhecer o que já foi vivenciado por determinados povos, no qual podemos vislumbrar novos conhecimentos e experiências sobre determinadas temáticas. Ricardo Oriá (2003, p. 139) infere que "Sem a memória, não encontraremos mais os ícones, símbolos e lembranças que nos unem à cidade e, assim, nos sentiremos deslocados e confusos". Partindo disso, acreditamos que a avó de Betina trouxe para a vivência da neta as lembranças que cooptou das suas memórias para que a mesma perpetuasse as recordações de sua ancestralidade.

A constituição da identidade de um sujeito ocorre no contexto no qual está inserido. Quer dizer, de acordo com as relações sociais e culturais que estabelece na sociedade, dos locais que habita e de sua visão de mundo e percepção. Sob a ótica de Gomes (2005, p. 41), "[...] a identidade não se prende ao nível da cultura. Ela envolve, também, os níveis sócio-político e histórico em cada sociedade".

Compreendemos identidade como Stuart Hall (2002, p. 13) explicita:

É definida historicamente, e não biologicamente. O sujeito assume identidades diferentes em diferentes momentos, identidades que não são unificadas ao redor de um "eu" coerente. Dentro de nós há identidades contraditórias, empurrando em diferentes direções, de tal modo que nossas identificações estão sendo continuamente deslocadas. [...] A identidade plenamente unificada, completa, segura e coerente é uma fantasia. Ao invés disso, à medida que os sistemas de significação e representação cultural se multiplicam, somo confrontados por uma multiplicidade desconcertante e cambiante de identidades possíveis, com cada uma das quais poderíamos nos identificar - ao menos temporariamente. (HALL, 2002, p. 13).

Posicionar-se na sociedade brasileira, onde o racismo estrutura as relações sociais, e assumir seu local de pertencimento, sua identidade negra, é deixar sua face a mostra sob todos os âmbitos. João Carlos Nogueira (2002, p. 47) expõe que "As relações sociais no Brasil são também historicamente marcadas pela violência no campo, no mundo 
urbano, nas relações de gênero e classe, de raça, cor, de geração, opção sexual, pela opressão como forma de intimidação e todo tipo de preconceitos".

Assim, a construção identitária do negro ocorre de forma muito particular, pois, apesar de estarmos no século XXI, o racismo, o preconceito racial e a discriminação ocorrem de forma evidente no país e as desigualdades sociais estão cada vez mais aferroando o povo negro. O racismo e a discriminação são, nas palavras de Nogueira (2002, p. 51), "elementos dinâmicos nas sociedades e nas relações sociais e interpessoais, ultrapassam as fronteiras de um ou outro marco histórico. Todavia, os alvos, as vítimas permanecem as mesmas, ou seja, os grupos discriminados permanecem hierarquizados na estrutura social". Para Gomes (2005), reconhecer-se em uma determinada identidade é se afirmar ante a sociedade, é ser pertencente a um grupo social de referência. Acerca do engendramento da identidade negra, a autora destaca que "[...] é entendida, aqui, como uma construção social, histórica, cultural e plural. Implica a construção do olhar de um grupo étnico/racial ou de sujeitos que pertencem a um mesmo grupo étnico/ racial, sobre si mesmos, a partir da relação com o outro" (GOMES, 2005, p. 43).

Isto é, a identidade negra é um constructo social, que está interligada com o plano simbólico dos valores, costumes, crenças, rituais, linguagens e dentre outros (GOMES, 2012. Gomes (2012, p. 2-3) reitera que "é um processo construído historicamente em uma sociedade que padece de um racismo ambíguo e do mito da democracia racial. Como qualquer processo identitário, ela se constrói no contato com o outro [...]”.

A história de Betina (GOMES, 2009) está atrelada ao costume que foi passado por seus ancestrais - de sua avó que aprendeu com sua mãe e assim sucessivamente no ato de trançar o cabelo crespo. Sob a ótica de Gomes (2002a, p. 43), "O uso de tranças é uma técnica corporal que acompanha a história do negro desde a África. Porém, os significados de tal técnica foram alterados no tempo e no espaço". Atualmente, as técnicas de trançar os cabelos crespos se alteraram: quando criança, utilizam as miçangas coloridas; quando adultas, algumas mulheres negras optam por fazer uso de trançados diferentes ou, também, por alisar o cabelo. $\mathrm{O}$ excerto que segue ilustra o que dissertamos sobre a experiência do negro com seu cabelo.

As experiências do negro em relação ao cabelo começam muito cedo. Mas engana-se quem pensa que tal processo inicia-se com o uso de produtos químicos ou com o alisamento do cabelo com pente ou ferro quente. As meninas negras, durante a infância, são 
submetidas a verdadeiros rituais de manipulação do cabelo, realizados pela mãe, tia, irmã mais velha ou pelo adulto mais próximo. As tranças são as primeiras técnicas utilizadas. Porém, nem sempre elas são eleitas pela então criança negra - hoje, uma mulher adulta - como o penteado preferido da infância (GOMES, 2002a, p. 43).

Na sociedade brasileira, por vezes, o cabelo negro é motivo para piadas pejorativas que $\mathrm{o}$ atinge de forma violenta, concretizando o racismo existente nas relações sociais. Gomes (2012, p. 3) expõe que "o cabelo negro, visto como 'ruim', é expressão do racismo e da desigualdade racial que recai sobre esse sujeito. Ver o cabelo do negro como "ruim" e do branco como 'bom' expressa um conflito". Corroboramos, ainda, com o pensamento da autora quando explicita que "O cabelo crespo na sociedade brasileira é uma linguagem e, enquanto tal, ele comunica e informa sobre as relações raciais. Dessa forma, ele também pode ser pensado como um signo, pois representa algo, distinto de si mesmo" (GOMES, 2002c, p. 97). Sendo assim, evidenciamos que o negro é acometido por atos racistas diariamente, fato lamentável que torna o país cada vez mais retrógrado, longe de se tornar igualitário e dito "justo" para todos.

No Brasil, o padrão idealizado de beleza advém do branco $^{2}$. É da população branca que o estereótipo é dito adequado para ser "aceito" na sociedade. Se não tem o corpo ideal ou se tem cabelo crespo, o indivíduo não é considerado partícipe do local que se encontra inserido, ou seja, da sociedade. O corpo negro é marcado pelos tensionamentos históricos que antecederam as gerações presentes no século XXI. Modificar o cabelo crespo, deixá-lo liso ou black power, fazer tranças, penteados diferentes ou simplesmente deixar-se permitir ter o cabelo que desejar, colorido ou somente negro; ter os lábios grossos, boca alargada, nariz achatado, rosto redondo, olhos pretos grandes ou pequenos; possuir um corpo com quadril largo e cintura fina, ser magra, ser gorda, baixa, alta ou mediana: são todas características que marcaram a trajetória do negro e respaldam a constituição da sua identidade. Portanto, “[...] para o negro, a intervenção no cabelo e no corpo é mais do que uma questão de vaidade ou de tratamento estético. É identitária" (GOMES, 2012, p. 3).

Partindo dessa premissa, o corpo negro e o cabelo crespo "[...] podem ser considerados expressões e suportes simbólicos da identidade negra no Brasil [...] possibilitam a construção social, cultural, política e ideológica de uma expressão criada no seio da comunidade negra: a beleza negra" (GOMES, 2012, p. 2).
2 Ver: Entre o encardido, o branco e o branquíssimo: branquitude, hierarquia e poder na cidade de $S P$, de Lia. Vainer Schucman (2014). 
$\mathrm{Na}$ narrativa analisada, a personagem desde a infância possui conhecimento e consciência que é uma mulher negra, que tem cabelos crespos, olhos grandes e pretos, rosto redondo e lábios grossos. A avó busca fortalecer na neta as heranças dos ancestrais, em especial, a arte de trançar cabelos crespos. A identidade negra de Betina é alicerçada positivamente, porém, Gomes (2002b, p. 41) alerta-nos que "Não é fácil construir uma identidade negra positiva convivendo e vivendo num imaginário pedagógico que olha, vê e trata os negros e sua cultura de maneira desigual".

Betina em sua fase adulta é dona de um salão de beleza e nesse espaço reafirma a beleza negra das mulheres que frequentam o seu estabelecimento e demonstra para as mesmas que ser mulher negra e aceitar-se como é pode torná-las mais felizes. O salão de beleza, nas palavras de Gomes (2012, p. 8), é intitulado como "salões étnicos", que são:

[...] espaços privilegiados para pensar várias questões que envolvem a vida dos negros, dos mestiços e dos brancos. São espaços corpóreos, estéticos e identitários e, por isso, nos ajudam a refletir um pouco mais sobre a complexidade e os conflitos da identidade negra. Nos salões o cabelo crespo, visto socialmente como o estigma da vergonha, é transformado em símbolo de orgulho. (GOMES, 2012, p. 8).

Na percepção da autora, os salões étnicos são espaços de "resistência e da comunidade negra" (GOMES, 2003, p. 179), nos quais as mulheres negras e/ou povo negro constroem e desconstroem as suas identidades e, ainda, é um local em que a autoestima se torna mais elevada, onde o negro se visualiza de forma positiva, conseguindo perceber a sua própria beleza negra.

O racismo, o preconceito, a discriminação racial, as disparidades socioeconômicas e as desigualdades sociais e raciais são as chagas que a sociedade brasileira coloca sobre a população negra. O negro sofre racismo diariamente, seja da forma totalmente explícita ou implícita. Sobre o corpo do negro as marcas de injustiça, de opressão e desrespeito ocorrem de maneira excessiva. As mulheres negras, nesse contexto são infinitamente mais acometidas com atos discriminatórios que as mulheres brancas e, até mesmo, pelo homem negro, às vezes, a mulher negra é vista como inferior.

A verdadeira realidade da mulher é perpassada por lutas diárias para alcançar seu espaço na sociedade. As mulheres negras são compreendidas por Jurema Werneck (2010, p. 76) como sendo: 
[...] sujeitos identitários e políticos, são resultado de uma articulação de heterogeneidades, resultantes de demandas históricas, políticas, culturais, de enfrentamento, das condições adversas estabelecidas pela dominação ocidental eurocêntrica ao longo dos séculos de escravidão, expropriação colonial e da modernidade racializada e racista em que vivemos.

As mulheres negras sofrem preconceito e racismo na sociedade brasileira, ultrapassando as questões de gênero. Infelizmente, a quantidade de melanina sob a pele do negro(a) é um dispositivo para que ocorram as ações racistas e sexistas. Mesmo ainda sendo oprimidas, elas estão buscando, e cada vez mais engajadas, por equidade social numa sociedade injusta que segrega a maior parte da população brasileira, que é aquela negra.

Betina evidencia a relevância primordial que o cabelo e a cor da pele detêm na construção da identidade negra e do posicionamento do mesmo ao se colocar como pertencente de um grupo étnico-racial na sociedade brasileira. Lamentavelmente, vivemos um mito da democracia racial que instaura a não existência das desigualdades raciais que persevera no cenário brasileiro e do mundo e, ainda, serve de alicerce para inferiorizar, hierarquizar e oprimir os negros, indígenas e outros povos que não se enquadram no contexto do homem branco.

Compreendendo o significado do cabelo crespo e seu sentido na sociedade brasileira, reforçamos a fala de Gomes (2002c, p. 97), quando elucida que "[...] o entendimento do significado e dos sentidos do cabelo crespo pode nos ajudar a compreender e desvelar as nuances do nosso sistema de classificação racial, o qual, além de cromático, é estético e corpóreo". A partir dessa apreensão sobre a importância que o cabelo crespo tem para o povo negro e para a construção da identidade desse sujeito, que vivencia na pele exaustivamente os tensionamentos de se reconhecer como um homem, mulher, criança, adolescente e idoso(a) negro num país que é extremamente racista.

\section{Tecendo reflexões que não se findam por aqui...}

As discussões tra(n)çadas neste texto acerca da importância da literatura afro-brasileira para infância, sobre a significância da educação das relações étnico-raciais e, ainda, do quanto se é delicada a construção da identidade negra, buscamos suscitar no leitor reflexões pertinentes que abrangem as questões étnico-raciais no bojo da sociedade brasileira. 
Diante disso, tecemos diálogos com teóricos que discutem como o racismo estrutura as relações sociais e em como o mesmo nega o direito do sujeito. Na visão de Nogueira (2002, p. 48), "A negação do outro como sujeito de direitos permitiu fazer da diferença um instrumento para a perpetuação das desigualdades. E estas marcas sedimentaram a formação do Estado, dos espaços de poder e da sociedade". Ou seja, as desigualdades estão postas na sociedade e se fazem presentes, alicerçando a hierarquização e inferiorização que existe no Brasil com relação aos diferentes grupos étnico-raciais que constituem o país.

É notória a relevância da Lei $\mathrm{n}^{\circ} 10.639$, de 2003, no contexto educacional, instituindo a obrigatoriedade do ensino da História da África e da Cultura Afro-brasileira nos currículos da Educação Básica (BRASIL, 2003), versando desconstruir a ótica errônea sobre o negro nos livros didáticos e nas falas de muitos sujeitos e que, infelizmente, ainda perpetra as narrativas existentes na sociedade brasileira. A educação das relações étnico-raciais visa o desenvolvimento de cidadãos que promovam reflexões e ações que contribuam para o engendramento de uma sociedade que seja mais igualitária e não racializada. A constituição da identidade negra não se configura de forma linear, ela é constantemente formada e desconstruída a partir de como o indivíduo se vê perante a sociedade na qual está inserido.

Na história de Betina, a menina negra que se torna mulher negra, desde a infância por meio dos ensinamentos da avó, que se reconheceu assim e sendo pertencente desse grupo étnico-racial, percebemos que a sua constituição identitária ocorre desde a tenra infância, sendo perpassada pelas marcas positivas e não negativas de ser mulher e negra, apesar de viver numa sociedade em que a cor da pele e o tipo de cabelo classificam o sujeito, inferiorizando-o.

Betina, de Nilma Lino Gomes (2009), apresenta o protagonismo negro infantil na sua constituição textual e visual, tecendo um discurso em que os preconceitos raciais são (re)significados, possibilitando que ocorra a constituição identitária de negros e negras, desde a infância, sob uma perspectiva desprovida das marcas inferiorizantes advindas do racismo.

\section{Referências}

BERND, Zilá. Introdução à literatura negra. São Paulo: Brasiliense, 1988.

BRASIL. Lei $\mathrm{n}^{\circ}$ 10.639, de 9 de janeiro de 2003. Altera a Lei no 9.394, de 20 de dezembro de 1996, que estabelece as diretrizes e bases da educação nacional, para incluir no currículo oficial da Rede de Ensino a obrigatoriedade da 
temática "História e Cultura Afro-Brasileira", e dá outras providências. Diário Oficial da União, Brasília, DF, 10 jan. 2003.

BRASIL. Lei $\mathrm{n}^{\circ}$ 9.394, de 20 de dezembro de 1996. Estabelece as diretrizes e bases da educação nacional. Diário Oficial da União, Brasília, DF, 23 dez. 1996.

CANDIDO, Antonio. O direito à literatura: vários escritos. 5. ed. Rio de Janeiro: Ouro Sobre Azul, 2011.

DEBUS, Eliane. A temática da cultura africana e afrobrasileira na literatura para crianças e jovens. São Paulo: Cortez, 2017.

DUARTE, Eduardo de Assis. Literatura Afro-brasileira: um conceito em construção. In: AFOLABI, Niyi; BARBOSA, Márcio; RIBEIRO, Esmeralda (Orgs.). A mente afrobrasileira. Trenton, NJ; Asmara, Eritréia: África World Press, 2007. p. 103-112. Disponível em: <https://social. stoa.usp.br/articles/o037/3053/Literatura_Afrobrasileira_EDUARDO.pdf $>$. Acesso $15 \mathrm{dez} .2017$.

DUARTE, Eduardo de Assis. Por um conceito de literatura afro-brasileira. Terceira Margem, Rio de Janeiro, v. 14, n. 23, p. 113-138, jul./dez. 2010. Disponível em: <https:// revistas.ufrj.br/index.php/tm/article/view/10953>. Acesso em: 15 dez. 2017.

ECO, Umberto. Sobre a literatura. Rio de Janeiro: Record, 2003.

GOMES, Nilma Lino. Trajetórias escolares, corpo negro e cabelo crespo: reprodução de estereótipos ou ressignificação cultural? Revista Brasileira de Educação, Rio de Janeiro, n. 21, p. 40-51, set./dez. 2002a. Disponível em: <http://www.scielo.br/pdf/rbedu/n21/n21a03.pdf > . Acesso em: 11 dez. 2017.

GOMES, Nilma Lino. Educação e identidade negra. Revista Aletria: alteridade em questão. Belo Horizonte, v. 6, n. 9, p. 38-47, dez. 2002b, Disponível em: <http:// www.periodicos.letras.ufmg.br/index.php/aletria/article/ viewFile/1296/1392>. Acesso em: 11 dez. 2017.

GOMES, Nilma Lino. Cabelo e Cor da Pele: uma dupla inseparável. In: NEGROS; Núcleo de Estudos (Orgs.). Multiculturalismo e a Pedagogia Multirracial e Popular. Rio de Janeiro: Atilènde, 2002c. (Série Pensamento Negro em Educação, v. 8). p. 95-113.

GOMES, Nilma Lino. Educação, identidade negra e formação de professores/as: um olhar sobre o corpo negro 
e o cabelo crespo. Educação e Pesquisa, São Paulo, v. 29, n. 1, p. 167-182, jan./jun. 2003.

GOMES, Nilma Lino. Alguns termos e conceitos presentes no debate sobre relações raciais no Brasil: uma breve discussão. In: BRASIL. Ministério da Educação. Secretaria de Educação Continuada, Alfabetização e Diversidade. Educação anti-racista: caminhos abertos pela Lei Federal no 10.639/03. Brasília, DF: SEC, 2005. (Coleção Educação para todos). p. 39-62.

GOMES, Nilma Lino. Betina. Ilustrações de Denise Nascimento. Belo Horizonte: Mazza, 2009.

GOMES, Nilma Lino. Corpo e cabelo como símbolos da identidade negra. Ação Educativa, 2012. Disponível em: <http://www.acaoeducativa.org.br/fdh/ wp-content/uploads/2012/10/Corpo-e-cabelo-como-s\%C3\%ADmbolos-da-identidade-negra.pdf > . Acesso em: 11 dez. 2017.

GREGORIN FILHO, José Nicolau. Literatura infantil e juvenil, cultura e ensino. In: DEBUS, Eliane; JULIANO, Beatriz; BORTOLOTTO, Nelita (Orgs.). Literatura infantil e juvenil: do literário a outras manifestações estéticas. Tubarão: Copiart; Unisul, 2016. . p. 59-72.

HALL, Stuart. A identidade cultural na pósmodernidade. 7. ed. Rio de Janeiro: DP\&A, 2002.

IANNI, Octavio. Literatura e consciência. Revista do Instituto de Estudos Brasileiros, São Paulo, n. 28, 1988.

NEVES, Margarida de Souza. História e Memória: os jogos da memória. In: MATTOS, Ilmar Rohloff (Org.). Ler e escrever para contar: documentação, historiografia e formação do historiador. Rio de Janeiro: Access, 1998.

NOGUEIRA, João Carlos. A Construção dos Conceitos de Raça, Racismo e a Discriminação Racial nas Relações Sociais. In: NEGROS; Núcleo de Estudos (Orgs.). Multiculturalismo e a Pedagogia Multirracial e Popular. Rio de Janeiro: Atilènde, 2002c. (Série Pensamento Negro em Educação, v. 8). p. 45-62.

ORIÁ, Ricardo. Memória e ensino de História. In: BITENCOURT, Circe (Org.). O saber histórico na sala de aula. 8. ed. São Paulo: Contexto, 2003. p. 128-148.

ROSEMBERG, Fúlvia. Literatura Infantil e Ideologia. São Paulo: Global, 1985. 
SCHUCMAN, Lia Vainer. Entre o encardido, o branco e o branquíssimo: branquitude, hierarquia e poder na cidade de SP, São Paulo: Annablume, 2014.

SILVA, Petronilha Beatriz Gonçalves e. Aprender, ensinar e relações étnico-raciais no Brasil. Revistas Eletrônicas PUCRS. Porto Alegre/RS, ano 30, n. 3, p. 489-506, set./ dez. 2007. Disponível em: <http://revistaseletronicas. pucrs.br/ojs/index.php/faced/article/view/2745/2092>. Acesso em: 16 dez. 2017.

WERNECK, Jurema. Mulheres Negras: um olhar sobre as lutas sociais e as políticas públicas no Brasil. Rio de Janeiro: Criola, 2010. Disponível em: <www.criola.org.br/ pdfs/publicacoes/livro_mulheresnegras.pdf $>$. Acesso em: 11 dez. 2017.

Recebido em: 03-09-2018

Aceito em: 10-04-2020

Publicado em: 22-05-2020 